\title{
A review on systematic study of cellulose
}

\author{
S.P. Gautam¹, P.S. Bundela², A.K. Pandey ${ }^{3}$, J amaluddin ${ }^{4}$, M .K . Awasthi² and S. Sar saiya²* \\ ${ }^{1}$ Central Pollution Control Board, New Delhi, INDIA \\ ${ }^{2}$ Regional office, M.P. Pollution Control Board, Vijay Nagar, Jabalpur (M.P.), INDIA \\ ${ }^{3}$ Mycological Research Laboratory, Department of Biological Sciences, Rani Durgavati University, Jabalpur-(M.P.), \\ INDIA
}

${ }^{4}$ Yeast and Mycorrhiza Biotechnology Laboratory, Department of Biological Sciences, Rani Durgavati University, Jabalpur (M.P.), INDIA

*Corresponding author. E-mail: surendra_sarsaiya @yahoo.co.in

Abstract: This review attempts to bring together basic and systematic information which has been gathered on cellulose structure, types, principally that of native cellulose, over the last few decades. Even though advances have been made in the field of crystallography, powder crystallography cannot yield a definitive cellulose structure and single crystal diffraction is not possible due to the lack of suitable crystals. Knowledge obtained on the biosynthesis of native cellulose and on the polymorphy of cellulose and its derivatives help our understanding of ultrastructure. Many inconsistencies between early crystallographic studies of native cellulose have been clarified by the discovery that two polymorphs $(\alpha$ and $\beta$ ) of cellulose I exist. Models of the possible ultrastructural arrangements within native cellulose have been put forward over the decades; with advancement in technology, computer simulations of small and large systems are being created to test the viability of these ultrastructural models. It is hoped that this review will aid in the understanding of the complexity and uncertainties that still exist in this subject.

Keywords: Structure, Polymorphy, Cellulose, Biosynthesis, Ultra-structure

\section{INTRODUCTION}

Cellulose constitutes the most abundant renewable polymer resource available today world wide, representing about $1.5 \times 10^{12}$ tons of the total annual biomass production through photosynthesis. The amount of carbon fixed by photosynthesis using solar energy has been estimated at 100 billion tons per year and half of this as cellulose. Cellulose occupies a unique place in the annals of polymers. Over 150 years ago, Anselme Payen discovered and coined the name "Cellulose" isolated from green plants. Several reviews have been published on cellulose research (Preston, 1975, 1986; Sarko, 1987; Chanzy, 1990 and Okamura, 1991). Cellulose is a linear polymer of D-anhydroglucopyranose units linked by $\beta$-1, 4-glucosidic bonds, with a degree of polymerization ranging from 15 to 10,000-14,000 (Lin et al., 1981). Cellulose chains in the crystals are stiffened by inter and intra chains hydrogen bonds and the adjacent sheets which overlie one another are held together by weak van-der waals forces. In nature, Cellulose is present in a nearly pure state in a few instances where as mostly are combined with lignin and other polysaccharides (socalled Hemicelluloses).

At the molecular level, Cellulose is linear polymer of glucose. The number of glucose units in the cellulose molecules varies. The nature of cellulosic substrate and its physical state are important factors in its enzymatic hydrolysis. The cellulose nitrate (commonly misnamed nitrocellulose) was milestones in the field of biotechnology. Partially functionalized cellulose nitrate mixed with camphor as softner was one of the first polymeric materials used as a plastic and its well known under the trade name of celluloid. Cellulose nitrates of higher $\mathrm{N}$-content have used extensively for military purposes. Today's cellulose nitrate is the only inorganic cellulose ester of commercial interest.

\section{OCCURENCE}

The main source of cellulose is the polysaccharides in different types of plants often combined with other biopolymers. The primary occurrence of cellulose is the existing lignocellulosic material in forests, with wood as the most important sources. Other cellulose-containing materials include agricultural residue, water plants, grasses and other plant substances (Table 1) (Marchessault and Sundararajan, 1993, Van Soest, 1994 and Lynd et al., 1999, ). Besides cellulose, they contain hemicelluloses lignin and a comparably small amount of extractions (Tuomela et al., 2000). The chemosynthesis of functionalized cellulose by ring-opening polymerization of 3,6-di-O-benzyl- $\alpha$-D-glucopyranosa 
Table 1. Chemical composition of some typical cellulose-containing materials ${ }^{\mathrm{a}}$

\begin{tabular}{|c|c|c|c|c|}
\hline \multirow[t]{2}{*}{ Source } & \multicolumn{4}{|c|}{ Composition (\%) } \\
\hline & Cellulose & Hemicellulose & Lignin & Extract \\
\hline Hardwood & $43-47$ & $25-35$ & $16-24$ & $2-8$ \\
\hline Softwood & $40-44$ & $25-29$ & $25-31$ & $1-5$ \\
\hline Bagasse & 40 & 30 & 20 & 10 \\
\hline Coir & $32-43$ & $10-20$ & $43-49$ & 4 \\
\hline Corn cobs & 45 & 35 & 15 & 5 \\
\hline Corn stalks & 35 & 25 & 35 & 5 \\
\hline Cotton & 95 & 2 & 1 & 0.4 \\
\hline Flax (retted) & 71 & 21 & 2 & 6 \\
\hline Flax (unretted) & 63 & 12 & 3 & 13 \\
\hline Hemp & 70 & 22 & 6 & 2 \\
\hline Henequen & 78 & $4-8$ & 13 & 4 \\
\hline Istle & 73 & $4-8$ & 17 & 2 \\
\hline Jute & 71 & 14 & 13 & 2 \\
\hline Kenaf & 36 & 21 & 18 & 2 \\
\hline Ramie & 76 & 17 & 1 & 6 \\
\hline Sisa & 73 & 14 & 11 & 2 \\
\hline Sunn & 80 & 10 & 6 & 3 \\
\hline Wheat straw & 30 & 50 & 15 & 5 \\
\hline
\end{tabular}

a- Adapted from Hon (1996)

1,2,3-orthopivate has been experimentally realized (Pandey et al., 2008). The non-biosynthetic preparation of cellulose of a molecular weight of $6300 \mathrm{~g} \mathrm{~mol}^{-1}$ was described involving an enzymatic polymerization using $\beta$-D-cellubiosyl fluoride as a substrate for purified cellulose, in a mixture of acetonitrate and acetate buffer at $\mathrm{pH} 5$.

\section{CHARACTERIZATION OF CELLULOSIC MATERIALS}

Cellulose is a heterogeneous raw material that makes modeling cellulolytic enzyme hydrolysis difficult. The most common celluloses are Cellulose I and II. Cellulose I is the native form of Cellulose found in Cotton, ramie, wood, Jute and flax. The cellulose chains are arranged so that the glucopyranose ring is parallel to the bc plane of the crystal (Ott et al., 1954; Gardner and Blackwell, 1974, ). This gives distinctly different characteristics between the two crystal faces with exposed glucopyranoside rings and the other faces. The binding of cellobiohyrolase and endoglucanose has been suggested to favor the faces with exposed glucopyranoside rings (Vyas, 1991; Reinikainen et al., 1995; Linder et al., 1995 and Tormo et al., 1996).

Cellulose II is a "Swollen" form of cellulose made by alkali treatment of Cellulose I. the Cellulose chains are rotated $30^{\circ}$ from parallel to the ab crystal face. Although this 2-chain cell model is correct for most cellulose, some require an 8-chain cell model. The two most dominating characterization of cellulose are the specific surface area, SSA, and the crytallinity index, CrI. Specific surface area is defined as the amount of surface area per mass of cellulose. Crystallinity index is the relative amount of crystalline cellulose (Lee and Fan, 1982). In biomass, cellulose is closely associated with hemicellulose and lignin. Agricultural residues are compost of 30-40\% cellulose, $25-35 \%$ hemicellulose and 10-15\% lignin with the remaining percentage in protein, simple sugar and minerals. Cellulose is naturally semi-crystalline with regions of high crystallinity averaging approximately 200 glucose residues in length separated by amorphous regions. Bacterial Micro-crystalline cellulose (BMCC) is the most completely characterized cellulose available. It is recovered as small particles from Blue-green algae such as Valonia macrophysa or Acetobacter xylinum. These particles are nearly $100 \%$ crystalline Cellulose.

\section{STRUCTURE OF CELLULOSE}

Cellulose is totally insoluble in water. It is polydisperse linear homopolymer, consisting of region and enantioselectivily $\beta-1,4$ glycosidic linked Dglucopyranose units (So called anhydroglucosa units [AGU] ). It has been shown by ${ }^{1} \mathrm{H}-\mathrm{NMR}$ spectroscopy (Blackwell and Marchessault, 1971 and Blackwell, 1982). The Polymer contains free hydroxyl group at the C-2, C3 and $\mathrm{C}-6$ atoms. Based on the $\mathrm{OH}$ groups and oxygen atoms of both the pyranose ring and the glycosidic bonds, ordered hydrogen bond systems from various types of supramolecular semi-crystalline structures (Atalla et al., 1993 and Brown et al., 2000) (Fig. 1).

\section{HYDROGEN BONDING}

Both intra and intermolecular hydrogen bonding occurs in cellulose the presence of intramolecular hydrogen bond is of high relevance with regard to the single chain conformation and stiffness. The existence of hydrogen bonds between O-3-H and O-5 (2.75 $\AA$, means of neighboring AGU) of the adjacent glucopyranose units 


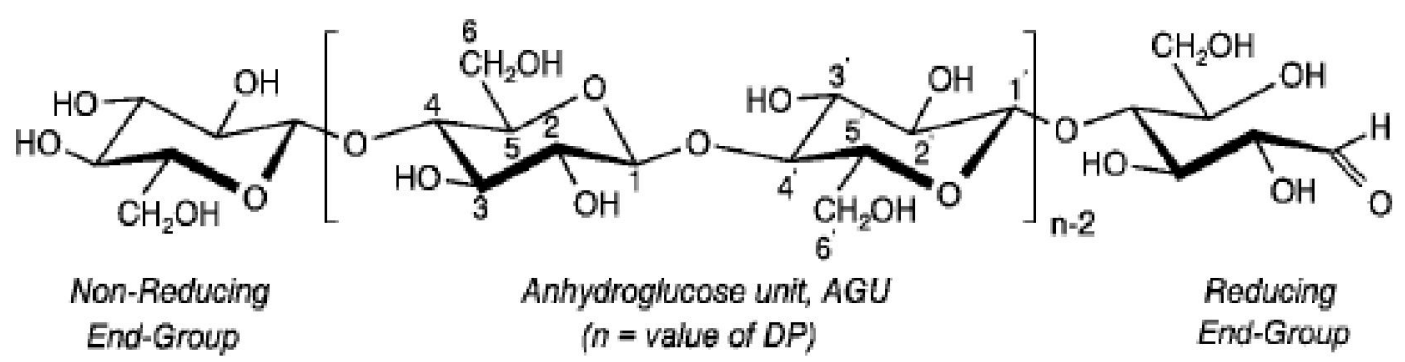

Fig. 1. Structure of cellulose.

and O-2-H and O-6' (2.87 ̊) in native crystalline cellulose (cellulose I) can be concluded from X-ray diffraction and NMR and IR spectroscopical data.

In cellulose II crystallines, the hydrogen bonds are essentially the same as those proposed for cellulose I, considering the $\mathrm{O}-3-\mathrm{H}$ and $\mathrm{O}-5$ ' (2.69 $\AA$ ) hydrogen bond. The intermolecular hydrogen bonding in cellulose is responsible for the sheet like nature of the native polymer. The intermolecular hydrogen bonding in cellulose II is significantly more complex compared to that of cellulose I. When considering hydrogen bonding, it is essential to note the conformation of the $\mathrm{C}$ (6) hydroxymethyl group. There are three possible minimum energy orientations for this substituent to the pyranose ring; trans-gauche ( $\mathrm{tg})$, gauche-trans (gt) and gauchegauche (gg), as illustrated in Fig. 2 (Shefter and Trublood, 1965). The reason for the difference in stability between these three staggered conformers is the relative proximity of the oxygen and carbon substituents. Both cellulose I and cellulose II have been studied in depth to decipher any pattern in their hydroxymethyl groups which may exist. Models of cellulose with each of the three orientations ( $\mathrm{tg}$, gt and gg) were compared to X-ray data to obtain the best fit. This fit may be described as the model with the lowest reliability factor (R). For cellulose I, a tg orientation gave the best fit (Gardner and Blackwell, 1974a) with the $\mathrm{R}$ value for $\mathrm{tg}$, gt and gg models being $0.242,0.292$ and 0.349 , respectively. For cellulose II, both regenerated (Buleon and Chanzy, 1978) and mercerized (Kolpak and Blackwell, 1976) forms were reported to have a gt conformation throughout the cellulose chain at the corner of the unit cell, but a tg arrangement for the centre chain. However, some rotation about the suggested minimum orientations (tg, gt and gg) was accepted as being possible. The majority view, expressed in the literature, is that cellulose I has a tg conformation and cellulose II has a gt conformation throughout the chains (Woodcock and Sarko, 1980, Okamura, 1991).

Derived from the study of hydroxymethyl orientations, intra- and inter-chain hydrogen bond patterns were suggested for cellulose I and II. The former has two intramolecular hydrogen bonds at $(\mathrm{O}) 5-(\mathrm{OH}) 3^{1}$ and $(\mathrm{OH})$ 2-(O) $6^{1}$ and an interchain hydrogen bond between $(\mathrm{O}) 6$ (O) 311 as shown in Fig. 14 (Tsuboi, 1957; Mann and Marrinan, 1958 and Liang and Marchessault, 1959). Cellulose II is reported as having intrachain hydrogen

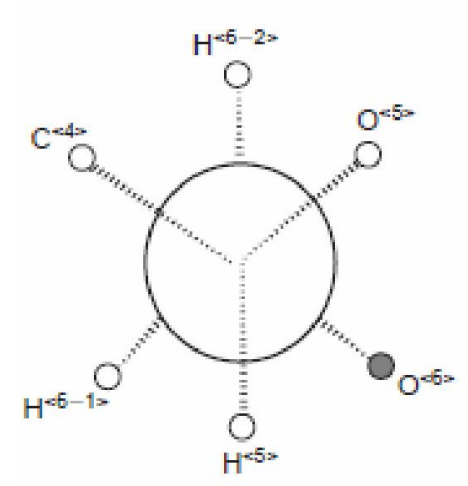

(a)

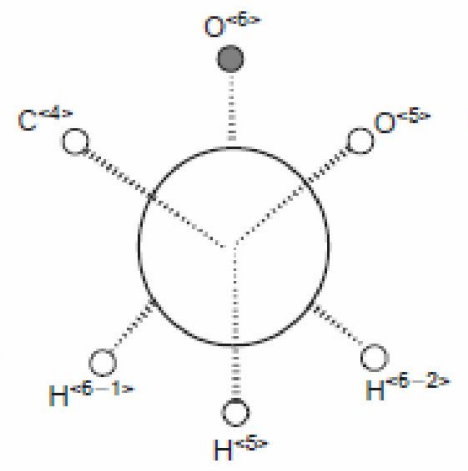

(b)

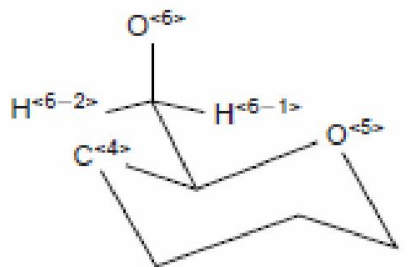

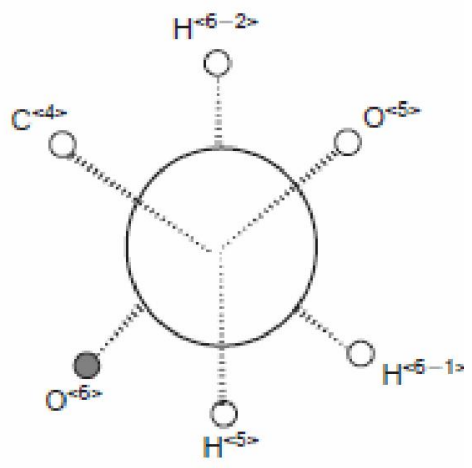

(c)

Fig. 2. The three most probable rotational positions of the hydroxymethyl group: (a) gt, (b) gg, (c) tg. 

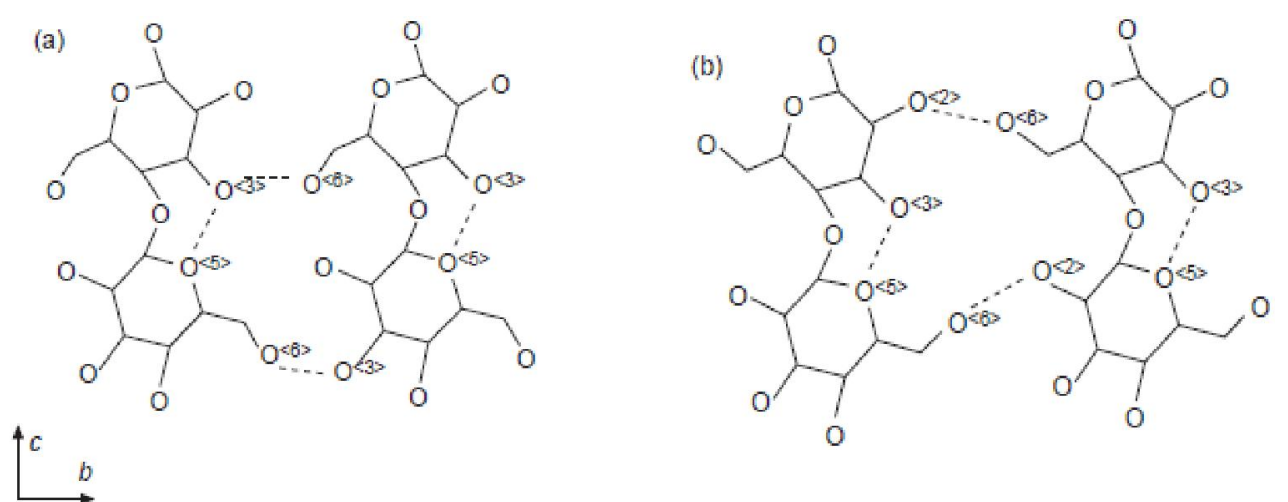

Fig. 3. Hydrogen bonding pattern for (a) cellulose I and (b) cellulosell.

bonding at $(\mathrm{OH}) 3-(\mathrm{O}) 5^{1}$ and an intermolecular hydrogen bond at $(\mathrm{OH}) 6-(\mathrm{O}) 2^{11}$ for corner chains and $(\mathrm{OH}) 6-(\mathrm{O}) 3^{11}$ for centre chains. An extra dimension was also added to the hydrogen bonding in cellulose II over cellulose I, in the form of an inter-sheet interaction between $(\mathrm{OH}) 2$ (corner chain) $\pm(\mathrm{O}) 2^{11}$ (centre chain), absent in native cellulose. The lengths of the hydrogen bonds in cellulose I are reported to be $0.275 \mathrm{~nm}$ (Tasker et al., 1994) (Fig 3). Cellulose III $_{I}$ has intramolecular hydrogen bonds between $(\mathrm{OH}) 3-(\mathrm{O}) 5 \mathrm{I}$ and $(\mathrm{O}) 2-(\mathrm{OH}) 61$ and intermolecular associations between $(\mathrm{O}) 3-(\mathrm{O}) 6^{11}$ as in cellulose I. For celluloses IVI and IVII, in addition to the usual two intramolecular hydrogen bonds present in most of the other crystalline celluloses, both polymorphs seem to be well established by the intermolecular hydrogen bonding along the 020 plane. Differences in the hydrogen bonding patterns reported for models of cellulose I and II are not solely derived from deviations in hydroxymethyl conformation but also from the fact that the polarity of the chains are popularly thought to differ; a parallel arrangement (Gardner and Blackwell, 1974a) is attributed to cellulose I and an antiparallel arrangement is attributed to cellulose II.

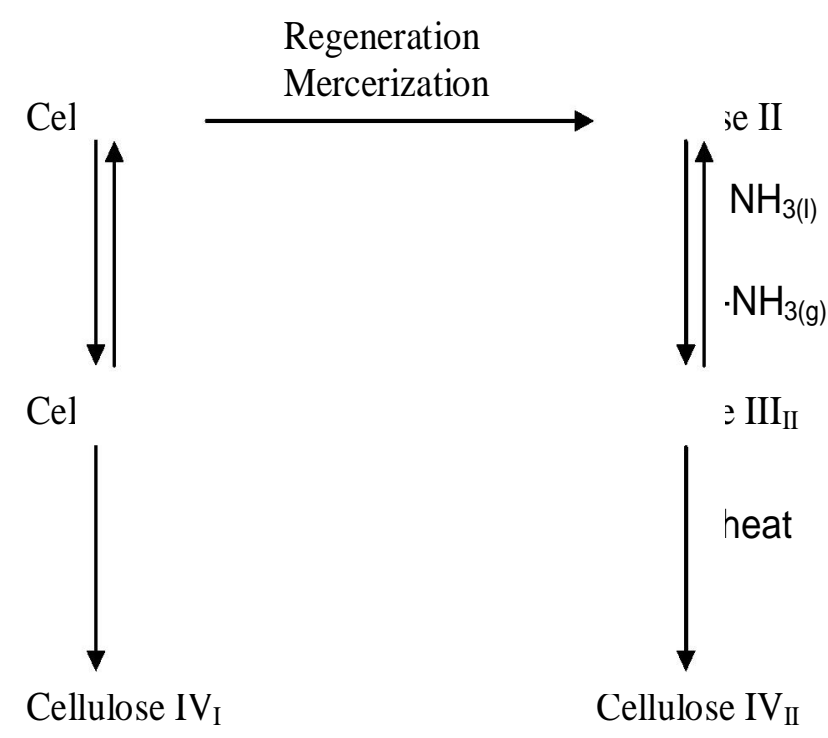

Fig. 4. Interconversion of the polymor phs of cellulose.
Intersheet associations are further affected by the fact that a relative shift of the centre and corner chains, along the fibre axis, has been observed (Gardner and Blackwell, 1974a). This amounts to $c=4$, or half a ring in length, for cellulose I or II. Cellulose III is reported to show a smaller shift of $0.09 \mathrm{~nm}$ as compared with $0.26 \mathrm{~nm}(\mathrm{c}=4)$.

\section{POLYMORPHY OF CELLULOSE}

The polymorphy of cellulose and its derivatives has been well documented. Six polymorphs of cellulose (I, II, III ${ }_{1}$, $\mathrm{III}_{11}, \mathrm{IV}_{1}$ and $\mathrm{IV}_{11}$ ) can be interconverted, as shown in Fig. 4 (Marchessault and Sarko, 1967, Walton and Blackwell, 1973, Marchessault and Sundararajan, 1983). The degree of crystallinity of cellulose (usually in the range of $40 \%$ to $60 \%$ ) covers a wide range and depends on the origin and pretreatment of the sample (Fink et al., 1987). Proof of the polymorphy of cellulose comes from nuclear magnetic resonance (NMR), infrared and diffraction studies (Blackwell and Marchessault, 1971, Blackwell, 1982).

\section{BIOSYNTHESIS OF CELLULOSE CELLULOSE I}

Cellulose exists in several crystal modifications, differing in unit cell dimensions and, possibly, in chain polarity. For crystalline native cellulose, i.e., cellulose I, Meyer, Mark, and Misch (Meyer and Mark, 1928, Meyer and Misch, 1937) proposed a unit cell of the crystal lattice (Fig 5). Numerous authors have suggested that the unit cell of native cellulose may depend on the source. Honjo and Watanabe (1958) concluded from low temperature electron diffractograms a doubling of the size of the unit cell. Sarko and Muggli (1974) agree to this eight-chain unit cell but state that the Meyer-Misch model also adequately represents most of the crystallographic evidence of native crystalline cellulose. In 1858, Carl von Nageli (von Nageli, 1858) established the crystallinity of cellulose in the first serious use of the polarizing microscope. This result was verified 80 years later with the aid of powder X-ray crystallography (Meyer and Misch, 1937). Elucidation of the crystal structure of cellulose began with Sponsler and Dore (1926), who 


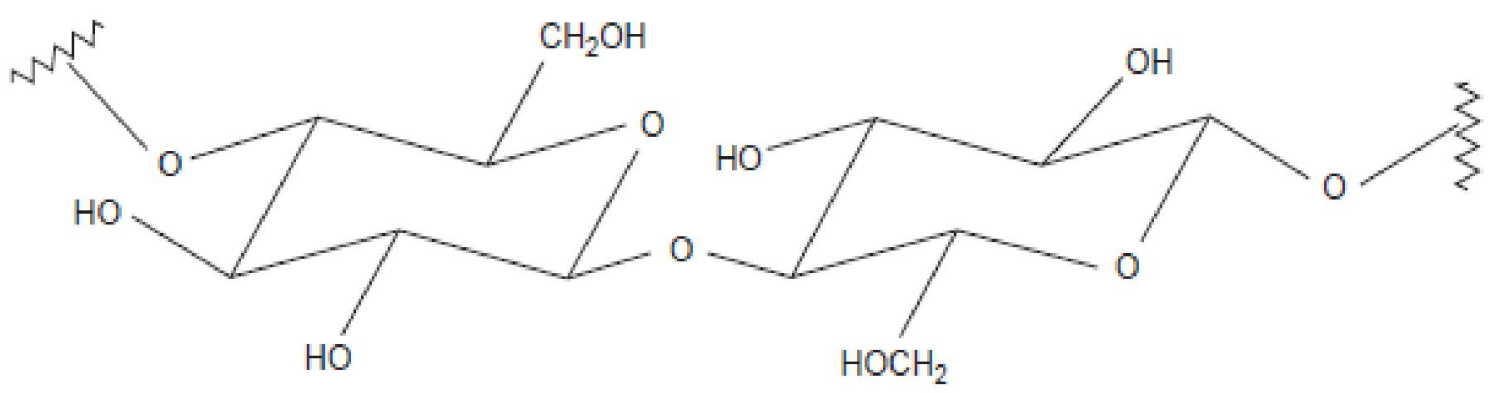

Fig. 5. Fragment (repeating unit) of a cellulose.

suggested a single chain unit cell with dimensions: $\mathrm{a}=$ $0.61 ; \mathrm{b}$ (fibre axis) $=1.034 ; \mathrm{c}=0.54 \mathrm{~nm}$; and $\beta=88^{\circ}$ (Fig 6). This model assumed an alternation of $(1 \rightarrow 1)$ and $(4 \rightarrow 4)$ links along the chain. A more acceptable unit cell was deduced by Meyer and Mark (1928) on the basis of different crystallographic parameters $(a=0.835 ; b=1.03$; $\mathrm{c}=0.79 \mathrm{~nm}$; and $\beta=84^{\circ}$ and improved in a later model by Meyer and Misch (1937). Meyer and Misch explained the fact that the unit cell parameter along the fibre axis direction is shorter than the fully extended length of a cellobiose residue by proposing a model with a kink, resulting from the formation of a hydrogen bond between the $\mathrm{C}(3)$ of one glucose residue and the ring oxygen of the next (Preston, 1986).

Atalla and Vanderhart (1989) showed that native cellulose consists of two different crystal structures, cellulose $\mathrm{I}_{\alpha}$ and $\mathrm{I}_{\beta}$, using high-resolution, solid-state ${ }^{13} \mathrm{C}$ NMR spectroscopical studies. There are differences in the resonances of the C-1 atoms. A singlet for cellulose $\mathrm{I}_{\alpha}$ and a doublet for cellulose $\mathrm{I}_{\beta}$ appears at about $106 \mathrm{ppm}$ This rather small difference indicates a different hydrogen bonding pattern of the glycosidic linkages. Bacterial cellulose and Valonia cellulose (from alga) contain a large amount of $\mathrm{I}_{\alpha}$ modification, while in ramie, cotton, and wood cellulose, the $I_{\beta}$ phase is the dominating

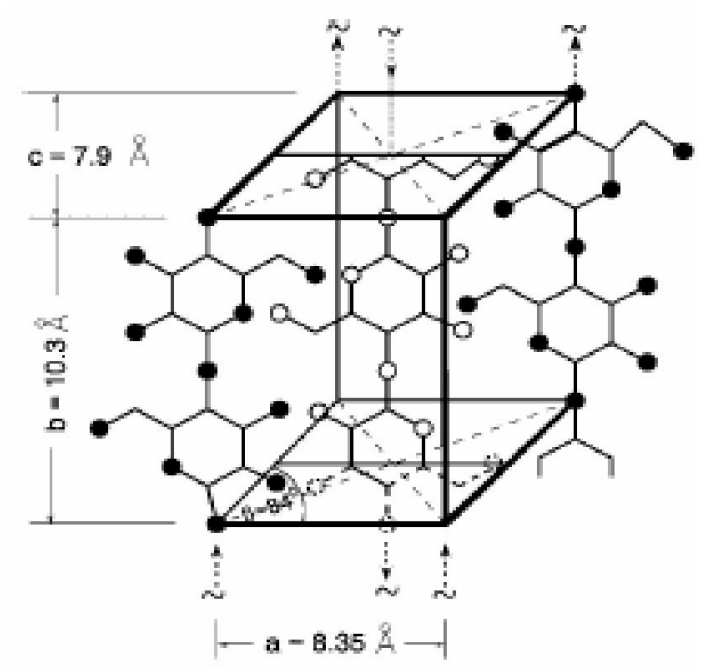

Fig. 6. U nit cell of cellulose I according to the Meyer-M isch model. modification. The $I_{\beta}$ modification is described as a triclinic P-1 structure, with one cellulose chain per unit cell, whereas the $\mathrm{I}_{\mathrm{a}}$ phase is assumed to be a monoclinic unit cell of the Meyer-Misch type (space group P- 2 with two chains per unit cell) as concluded from electron diffraction experiments (Sugiyama et al., 1991). According to Yamamoto and Horii (1994), the $\mathrm{I}_{\alpha}$ phase is metastabile and can be transformed (not completely, however) into the thermodynamically more stable $\mathrm{I}_{\beta}$ phase by annealing at $260^{\circ} \mathrm{C}$ to $280^{\circ} \mathrm{C}$.

Unit cell parameters for crystalline cellulose I are listed in Table 1. Variations between the results of different research groups may be explained by several factors:

(1) Technical advances improved the ability to measure the parameters.

(2) Parameters depend on the source of the cellulose and it has been suggested that this may be linked to taxonomy (Okano et al., 1989).

(3) Single-crystal diffraction is the only method that provides bond lengths, bond angles and characteristic geometry. It is the ultimate structural method. On the other hand, polymer X-ray studies, as in the case of cellulose, use powder crystallography. When carrying out powder X-ray crystallographic analysis the operator has to input assumptions to obtain results. Thus, the structure of cellulose cannot be determined with certainty

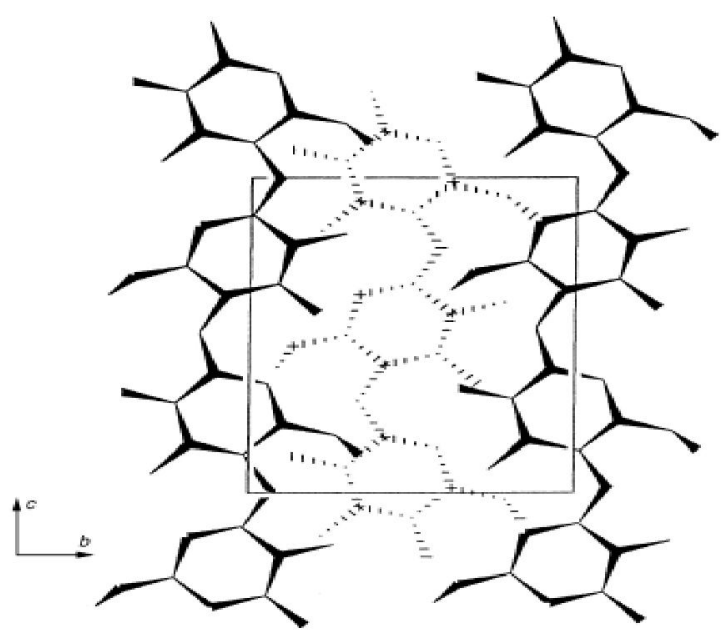

Fig.7. Projections of a two-chain model of cellulose I Valonia ventricosa) per pendicular to bc plane (Woodcock and Sarko, 1980). 
by X-ray data alone, as the results obtained are dependent on the model input.

(4) Degree of crystallinity of samples may be a factor.

(5) Sample purity, that is how many polymorphs of cellulose are present, is also pertinent.

When studying some very highly crystalline celluloses (e.g. Valonia ventricosa), a reasonably well resolved spectrum resulted, showing a slightly different diffraction diagram which was taken to indicate an eight-chain unit cell (Honjo and Watanabe, 1958). Dimensions given for this unit cell were quoted as twice those of a two chain unit cell; $\mathrm{a}=1.576 ; \mathrm{b}=1.642 ; \mathrm{c}$ (fibre axis) $=1.034 \mathrm{~nm}$; and $\gamma=96.8^{\circ}$ (Sarko and Muggli, 1974). Cotton, ramie, wood and other fibrous celluloses, of medium crystallinity, were found to be consistent with a two-chain monoclinic unit cell as shown in Fig. 3, that is a unit cell with one non- $90^{\circ}$ angle $\left(\mathrm{a}=\mathrm{b}=\mathrm{c}\right.$ and $\left.\gamma=\alpha=\beta=90^{\circ}\right)$, with dimensions: $\alpha=$ $0.778 ; \mathrm{b}=0.820 ; \mathrm{c}$ (fibre axis) $=1.034 \mathrm{~nm}$; and angle $\gamma=$ $96.5^{\circ}$ (Woodcock and Sarko, 1980). It was accepted that the two-chain unit cells of other native celluloses could very nearly be considered as sub-cells of the eight-chain Valonia unit cell. The unit cell contains a two ring portion of the ceKuløse chain/which is $1.034 \mathrm{~nm}$ in length, called the fibre repeat (Fig 7).

\section{CELLULOSE I ${ }_{\alpha}$ AND I ${ }_{\beta}$}

Evidence has been put forward for the existence of more than one polymorph of cellulose in native samples. Simon et al. (1988a) postulated that a form of crystalline cellulose existed near the surface of a crystal which differed from the structure to be found at the centre of the crystal.

These two crystalline forms were termed celluloses I and $I_{\beta}$ (Atalla and Vanderhart, 1989). Celluloses produced by primitive organisms were said to have the $\mathrm{I}_{\alpha}$ component dominant, while those produced by the higher plants have the $\mathrm{I}_{\beta}$ form dominant. $\mathrm{I}_{\alpha}$ and $\mathrm{I}_{\beta}$ were found to have the same conformation of the heavy atom skeleton, but to differ in their hydrogen bonding patterns. Horii et al. (1987) suggested that the two ${ }^{13} \mathrm{C}$ NMR spectra obtained for polymorphs $\mathrm{I}_{\alpha}$ and $\mathrm{I}_{\beta}$ correspond to the resonances for the two-chain and eight-chain unit cell regions of cellulose.

When the NMR spectral patterns of Valonia and Tunicin are examined (Belton et al., 1989; Sugiyama, 1992 and Yamamoto and Horii, 1993), it may be seen that Tunicin has a simpler spectrum than Valonia. The latter contains two overlapping spectra, $\mathrm{I}_{\alpha}$ and $\mathrm{I}_{\beta}$. It is possible to calculate the relative percentage of each of the polymorphs present. Tunicin possesses only the $I_{\beta}$ polymorph, and so gives the simpler spectrum where highly crystalline samples were used. Erata et al., (1995) found differences between the correlation peaks of $\mathrm{I}_{\alpha}$ and $\mathrm{I}_{\beta}$ cellulose in Cladophora which indicate essential structural differences.

\section{AM ORPHOUS CELLULOSE}

Wide-angle X-ray scattering has been used to study possible structures for amorphous cellulose. Diffraction studies show light and dark areas along a cellulose microfibril, which have been attributed to crystalline and amorphous cellulose, respectively. The simplest conceivable model has 'straight' cellulose chains

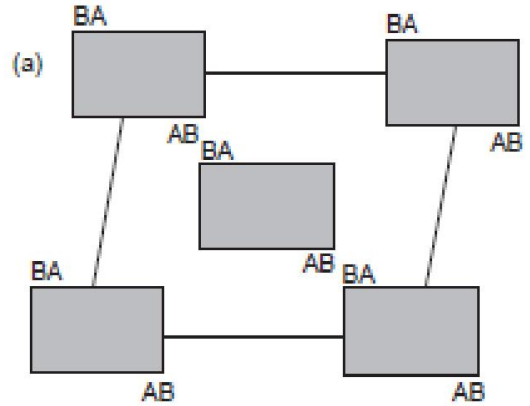

(b)
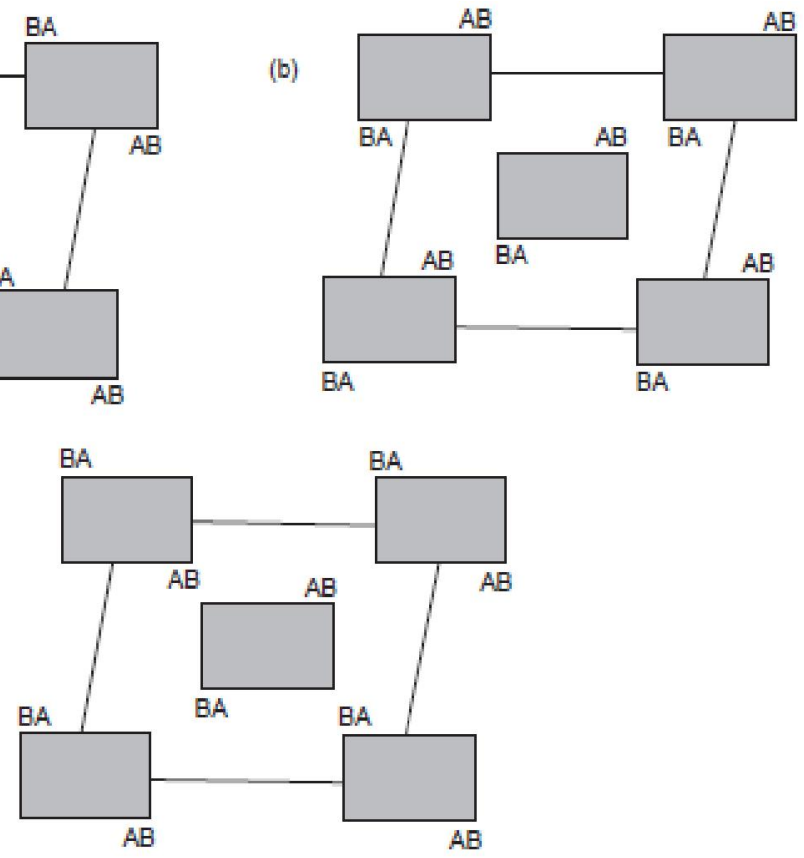

Fig. 8. The x-y projection of the unit cells of cellulose packed with a) 'parallel up', b) 'parallel down' and c) antiparallel chains. The interactions between the $A B$ points are different for the three types of packings. 
isotropically distributed in the sample (Fink et al., 1987). However, a bent and twisted chain was also suggested (Paakkari et al., 1989). In later research (Chanzy, 1990), it was shown that a slight curvature in the microfibril brings specific domains in and out of the Bragg diffraction conditions, producing the successive bright and dark domains along the microfibril axis. This implies that the cellulose microfibril may be a continuous crystalline structure and negates the use of light and dark areas observed in the diffraction patterns as evidence for amorphous areas. Valonia is a highly crystalline cellulose and, thus, frequently the object of study. Of the $600 \pm 1000$ parallel chains which may exist in a microfibril of Valonia, only $6 \pm 7 \%$ of the material is amorphous. Verlhac et al. (1990) suggested that the amorphous material consists mostly of surface chains, which in the large Valonia microfibril makes up a small percentage of the total. This may be linked to Valonia's low reactivity, (Debzi et al., 1991) denoted by a degree of substitution of only $1 \%$, when subjected to chemical micro-structural analysis (Verlhac et al., 1990). The reactant involved in this test was N,N-diethyl aziridinium chloride (DAC). For smaller microfibril, like wood, the percentage surface area is greater and approximately equals the percentage amorphous content: $30 \%$ surface hydroxyls versus $33 \%$ amorphous material. In the primary cell wall, the microfibril is very small and $80 \%$ of the chains are on the surface, and so according to this theory, there would be approximately $80 \%$ amorphous material in these samples. Bacterial cellulose has crystallinity of the order of $75 \%$ (Kulshreshta and Dweltz, 1973), and its crystals are around $5 \pm 6 \mathrm{~nm}$ in diameter. Assuming that these crystals have a nearly square cross-section, there are around 100 chains per crystal, with roughly 36 chains located at the crystal surface. Cotton is rated as being $40 \pm 45 \%$ crystalline and as having a crystallite width of $4 \pm 5 \mathrm{~nm}$ (Morosoff, 1974). A degree of substitution of $2.4 \%$ was measured for cotton (Verlhac et al., 1990). This may be compared with the result for Valonia outlined above, i.e. $1 \%$ degree of substitution and more than $90 \%$ crystalline. This phenomenon is unique to cellulose I. The situation may be complicated, however, by the fact that triclinic cellulose I is metastable and may provide a more probable site of reaction. The surface of crystalline cellulose or indeed areas of 'amorphous' cellulose probably still possess a degree of order. Thus 'amorphous' cellulose cannot be considered truly amorphous as, by definition, an amorphous material is one which is formless or lacks a definite shape.

\section{CELLULOSE II}

$\mathrm{X}$-ray and electron diffraction work has been carried out to clarify the unit cells of cellulose polymorphs I-IV. ${ }^{13} \mathrm{C}$ CP/MAS NMR spectra (Horii et al., 1982, Dudley et al.,
1983) show different signals for the $\mathrm{C}(4)$ and $\mathrm{C}(6)$ carbons of the polymorphs of cellulose. It was found that the polymorphs may be divided into two groups; those with a unit cell similar to that of native cellulose (I, III $_{\mathrm{I}}$ and IV $\mathrm{IV}_{\mathrm{I}}$ ) and those with a cellulose II type arangement (II, III $_{\text {II }}$ and $\left.\mathrm{IV}_{\mathrm{II}}\right)$. Thus, cellulose II has become an important focus of study, being the second most investigated form of cellulose. Preliminary work on cellulose II by Andress (1929) presented a two molecule unit cell (Fig. 6): $\mathrm{a}=$ $0.814 ; b=0.914 ; c=1.03 \mathrm{~nm} ;$ and $\gamma=62^{\circ}$. X-ray results for cellulose II are less reliable than those for cellulose I due to the large number of diffraction intensities which overlap each other (Buleon and Chanzy, 1978). Neutron diffraction studies (Ahmed et al., 1976) directed interest toward a larger unit cell containing eight molecules, with parameters: $\mathrm{a}=1 . .592 ; \mathrm{b}=1.822 ; \mathrm{c}$ (fibre repeat) $=1.031$ $\mathrm{nm} ; \gamma=117^{0}$; and symmetry which was close to, but not exactly, P2 . It must be remembered that cellulose II may be arrived at from cellulose I by two distinct routes, i.e. mercerization (alkali treatment) and regeneration (solubilization and recrystallization), and that even though the unit cells resemble each other closely, there are differences. The parameter for the regenerated product of ramie cellulose has been quoted as $0.8662 \mathrm{~nm}$ and the mercerized ramie cellulose product as $0.8588 \mathrm{~nm}$. The value of $\tilde{a}$ is greater for mercerized specimens than for most regenerated samples (Wellard, 1954). Also, as the degree of purity of samples used has been shown to be relevant, it should be noted that regeneration gives a higher level of conversion of cellulose I to cellulose II (Kolpak and Blackwell, 1976). Nyburg (1961) reported one example of naturally occurring cellulose II, in the genus Halicystis. Kuga et al. (1993) reported a mutant strain of Acetobacter xylinum as containing native folded-chain cellulose II. Another commonly studied aspect of cellulose II is the direction of the chains in the unit cell and the most prevalent view is that the two cellulose chains lie antiparallel to one another (Sarko and Muggli, 1974; Kolpak and Blackwell, 1976; Stipanovic and Sarko, 1976).

\section{CELLULOSE III}

Celluloses III $_{\mathrm{I}}$ and III $_{\mathrm{II}}$ may be made reversibly from celluloses I and II, respectively and the polarity of the resultant cellulose chains has been stated to resemble that of the starting material (Sarko, 1978; Sugiyama and Okano, 1989). A hexagonal unit cell is reported for cellulose III. Extensive research has been carried out on the reversible transformation of cellulose I into cellulose

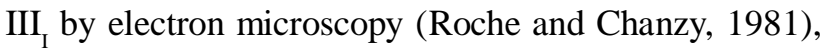
packing analysis (Chanzy et al., 1987), transmission electron microscopy (Chanzy et al., 1986), and X-ray diffraction (Sugiyama and Okano, 1989). The existence of liquid crystal type assembly of cellulose was used to investigate the transformation of cellulose I to cellulose 


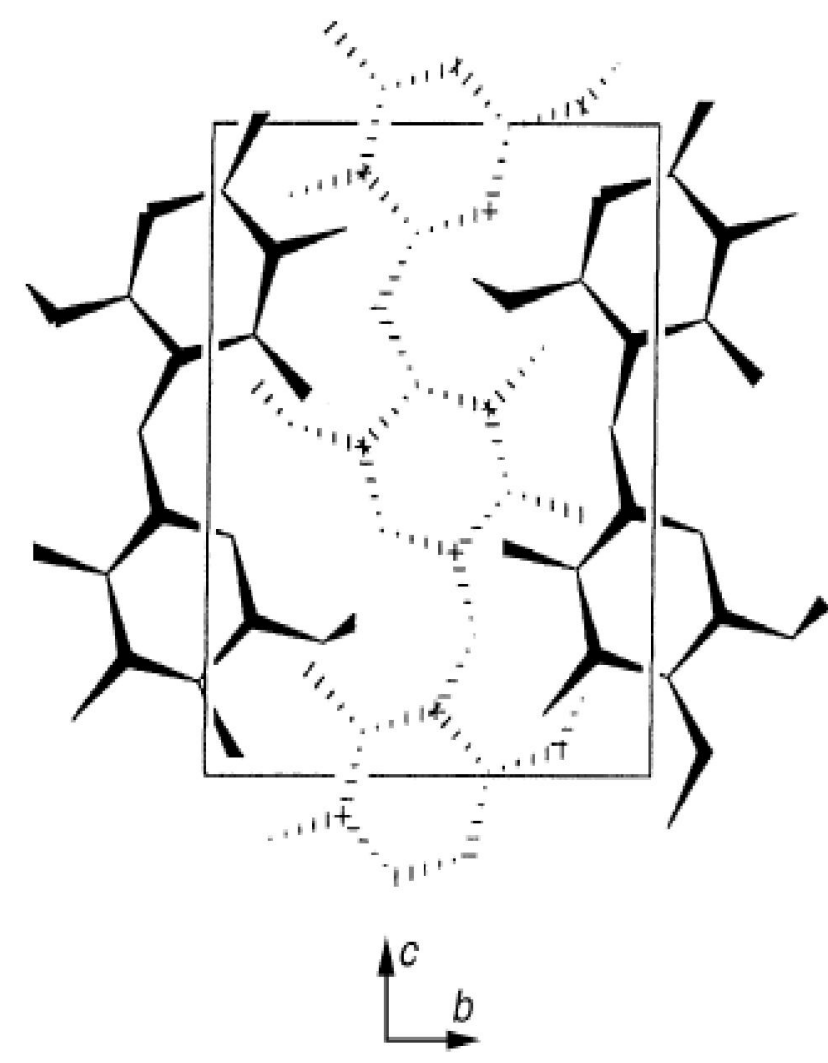

Fig. 9. Projections of cellulose II Fibre unit cell (Sarko and Muggli, 1974).

III $_{\text {I }}$ hrough the cellulose I-EDA complex (Roche and Chanzy, 1981, Reis et al., 1991). At the crystalline level, the conversion from Valonia I to Valonia III involved an extensive decrystallization and fragmentation of the cellulose crystals. During the conversion back to cellulose I, partial recrystallization took place but the distortion and fragmentation of the crystals was irreversible. Electron diffraction analysis showed that the unique, uniplanar-axial orientation of the crystalline cellulose microfibrils (Fig. 10a) was irreversibly lost during the swelling (Fig. 10b) and washing (Fig. 10c) steps leading to cellulose III. Following washing in methanol, the microfibril adopted a convoluted contour which contained small areas of crystallinity. The final product cellulose I (Fig. 10d), produced by hydrothermal treatment, had increased surface area and thus increased activity and larger domains of crystallinity than seen in the sample depicted in Fig. 10c. Celluloses I and III were studied by ${ }^{13} \mathrm{C}$ NMR and it was indicated that a reduction in the lateral dimensions of the crystallites occurred during the transformation from the former to the latter polymorph. Examination of the reversible complexation of Valonia cellulose with ethylene-diamine was carried out. This spectral study indicated that a conformational change occurs at $\mathrm{C}(6)$, during the cellulose I to complex transition. The peak corresponding to the $\mathrm{C}(6) \mathrm{OH}$ is $\mathrm{tg}$ in cellulose I ( $65.7 \mathrm{ppm})$ and possibly gt in the cellulose I-EDA complex (62.2 ppm). In cellulose IIII the relevant

peak occurs at $62.6 \mathrm{ppm}$. The regenerated cellulose I gave a spectrum which differed from that of the initial cellulose I. Electron diffraction studies show that the cellulose IEDA complex has organized contours and non-uniform crystallinity, shown by a non-white area, whereas cellulose IIII has defined crystallinity (Fig. 10c). The variability of hydroxylmethyl conformation indicated above is interesting as it may also be used to study other transformations such as those occurring during mercerization of cellulose I to cellulose II.

\section{CELLULOSE IV}

Celluloses $\mathrm{IV}_{\mathrm{I}}$ and $\mathrm{IV}_{\mathrm{II}}$ originate from celluloses I and II, respectively. In the latter instance it is best to use regenerated cellulose (Zeronian and Ryu, 1987). Cellulose III is reported as being very nearly tetragonal but the conversion into cellulose IV is, in most cases, only partial thus causing difficulties in obtaining reliable X-ray data (Buleon and Chanzy, 1980). One sample yielded the following parameters: $\mathrm{a}=0.8068 ; \mathrm{b}=0.7946 \mathrm{~nm} ; \tilde{a}=90^{\circ}$. In Gardiner and Sarko's analysis of celluloses $\mathrm{IV}_{\mathrm{I}}$ and $\mathrm{IV}_{\mathrm{II}}$ (Gardiner and Sarko, 1985) both polymorphs were said to crystallize in almost the same orthogonal unit cell, with parameters for cellulose $\mathrm{IV}_{\mathrm{I}}: \mathrm{a}=0.803 ; \mathrm{b}=0.813$; $\mathrm{c}($ fibre repeat $)=1.034 \mathrm{~nm}$ and for cellulose $\mathrm{IV}_{\mathrm{II}}: \mathrm{a}=0.799$; $\mathrm{b}=0.810$; and $\mathrm{c}$ (fibre repeat) $=1.034 \mathrm{~nm}$. A P1 space group was suggested to be most probable for both polymorphs.

\section{ALKALI-CELLULOSE}

The majority view in the literature is that the polarity of cellulose chains differs between cellulose I and cellulose II. That means that cellulose I is parallel but cellulose II is antiparallel. In the mercerization process (the treatment of cellulose I with alkali, to achieve cellulose II) no

(a)

(c)

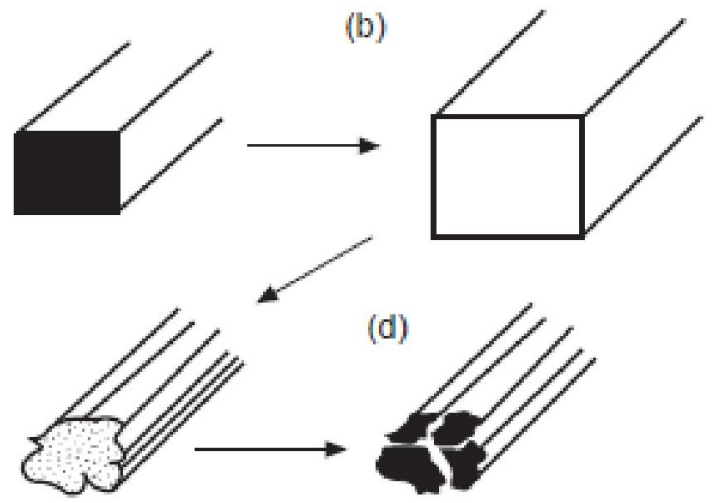

Fig. 10. Schematic representation of a Valonia microfibril (MF) undergoing swelling in ethylene diamine (ETD ): a) I nitial single M F crystal (in black); b) Swollen M F, after uptake of one ETD molecule per glucose residue; c) Shrunken M F of Valonia III ${ }_{1}$ resulting from the washing in methanol of (b); d) M F as in (c) but after the hydrother mal treatment leading to regenerated Valonia I. 
solubilization occurs, which seems to imply that the fibrous structure of the cellulose would be maintained. In order to improve the understanding of this transformation, the changes that occur in cellulose during alkali treatment were examined (Okano and Sarko, 1985, Hayashi et al., 1989, Nishimura et al., 1991a, b). It was found, by Okano and Sarko (1985), that five unique alkalicelluloses could be generated reproducibly and that they could be divided into two types, based on their crystallographic fibre repeat (Okano and Sarko, 1984). Na-celluloses I, III and IV all exhibited a $1.0 \mathrm{~nm}$ repeat, while Na-celluloses IIA and IIB showed a $1.5 \mathrm{~nm}$ repeat and a three-fold helical chain conformation, not seen in crystalline celluloses. All the alkali celluloses had a reasonable degree of crystallinity and a high degree of fibrous orientation. It is difficult to reconcile the claimed change in polarity with the mercerization process. As Na-cellulose I cannot be reconverted to cellulose I, it was deduced that Na-cellulose I possesses an antiparallel arrangement: the same chain polarity which is thought to exist in cellulose II. This may explain how cellulose I (parallel) can be converted to cellulose II (antiparallel) without solubilizing the cellulose. Hayashi et al. (1989) discussed in excess of nine polymorphs of alkalicellulose, which could be formed from cellulose I, II and/ or III. It was deduced from these results that the hypothesis of the change in chain conformation, as the cause of the irreversibility, is more probable than that of the chain arrangement. The problem with this argument is that the difference in the conformational energy between the two chain conformations is too small to bring about irreversibility. It has been stated that there are two types of microfibrils in Valonia, that is those which have cellulose chains with their 14 glycosidic bonds uniformly in the positive $\mathrm{z}$ direction and those which have them uniformly in the negative $\mathrm{z}$ direction (Revol and Goring, 1983). This is in line with Figs 4a and 4b respectively. Cellulose microfibrils are arranged in a crisscross like arrangement, giving high strength to the material (Fig. 11).

Diffraction studies of the cross-sections of microfibrils showed individual black areas. These are supposed to correspond to microfibril ends. The direction of the microfibril can be determined by recording a diffraction diagram down the individual microfibril (Kolpak et al., 1978). In a small bundle of microfibrils various directions are observed (Fig. 12). The $+\mathrm{z} /-\mathrm{z}$ directions of the microfibrils occur in a statistical distribution. This phenomenon may be used to explain solid-state conversion of native cellulose II during mercerization (Sarko, 1987). Rearrangement of the chains in the original unidirectional bundles of microfibrils of cellulose I give mixed direction microfibrils in cellulose II. Na-cellulose I was studied by X-ray crystallography (Nishimura et al., 1991a) and assigned a four chain unit cell with $P 2$ space group $(\mathrm{a}=0.883 ; \mathrm{b}=2.528 ; \mathrm{c}$ (fibre repeat $)=1.029 \mathrm{~nm}$; all angles $90^{\circ}$ ). An antiparallel arrangement of chains was slightly favoured over a parallel one. Hydroxymethyl conformations were found to be tg in the ' $+\mathrm{z}$ ' chains and $\mathrm{gt}$ in the ' $\mathrm{z}$ ' chains.

\section{DENSITY AND DEGREE OF CRY STALLINITY}

The density of cellulose crystals, which may be determined by crystallography, is related to the structure of the substance. The density of crystalline cellulose, as found in a single crystal, is $1.59 \mathrm{~g} \mathrm{~cm}^{-3}$, whereas that of pure natural fibre cellulose reaches only $1.55 \mathrm{~g} \mathrm{~cm}^{-3}$ (Hermans, 1949). Hermans and Weidinger (1949) also found the so-called crystallinity derived from X-ray scattering was only $70 \%$ at most in native fibres, while the remaining percentage of the cellulose was said to be 'amorphous'. Degree of crystallinity may also be estimated by infrared spectroscopy on the basis of the relative height of certain bands (Fengel, 1992). Thus, the lower density found in natural fibre may be attributed to the presence of amorphous or less ordered cellulose.

\section{CELLULOSE ULTRASTRUCTURE}

In plants, polysaccharides exist in the primary, secondary and tertiary cell walls. The tertiary cell wall contains a lower level of cellulose, being composed mainly of xylan. Primary and secondary walls differ in the arrangement of the cellulose chains. The former is less ordered and essentially composed of cellulose chains running in all directions within the plane of the wall. In the secondary cell wall, the cellulose chains are grouped in microfibrils which are parallel, giving a more densely packed arrangement, and are aligned more or less with the fibre axis. As technology has developed, the features of the cell wall have been observable in more detail. High

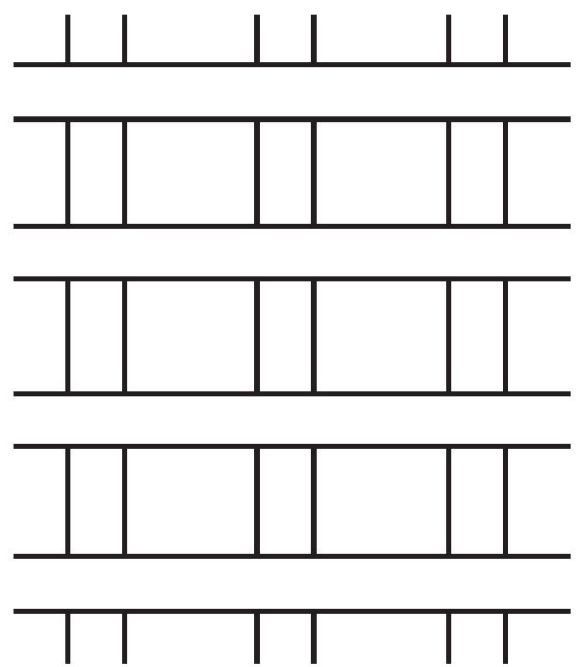

Fig 11. C riss-cross arrangement of native cellulose. 
One Microfibril

$\circ$

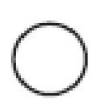

$\circ$
Second Microfibril

\section{o}

$\circ$

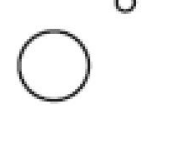

A Bundle of Microfibrils

$\circ$

$\circ$

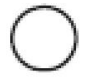

0

O

Fig 12. A schematic representation of the end of single micro $₫$ brils and of a bundle of micro $₫$ brils as seen by a diffraction pattern.

resolution electron microscopy lattice imaging shows the crystalline organization of cellulose in wood fibrils. Negative staining (Heyn, 1966; Woodcock and Sarko, 1980) used in conjunction with electron microscopy shows occasional points along the fibril at which the heavy metal stain seemed to penetrate: it was postulated that non-glucose residues were located in these areas. This theory could be seen to be supported by the discovery, in 1961, that up to $50 \%$ of some sections of these native cellulose fibrils were composed of nonglucose units. However, these early workers had not isolated pure cellulose microfibrils but were working with fibrils which were a combination of cellulose and hemicellulose (Dennis and Preston, 1961), and the nonglucose units are derived from the hemicelluloses. Breakdown of fibrils by chemical treatment (Dennis and Preston, 1961) yields colloidal celluloses which contain, at most, only traces of non-glucose sugars, even though these may be abundant in the parent fibrillar material. This is because the material isolated by chemical means are cellulose fibrils, almost free from hemicellulose contaminants. The resultant cellulose rods, which were measured as approximately 135 glucose residues in length, were thought to represent crystallites of the microfibril. Despite development in microscopic techniques such as scanning electron microscopy (Fengel and Stoll, 1989), atomic force microscopy (Hanley et al., 1992) and scanning tunnelling microscopy (Kuutti et al., 1995) the chain length of such a large molecule as cellulose is still rather difficult to measure. The cellulose molecule in wood was found to be approximately $3500 \pm 5000 \mathrm{~nm}$ in length when determined by degree of polymerization, as calculated by weight of cellulose molecules isolated by a variety of methods (Fengel and Wegner, 1989), whilst the average size of each crystallite has been determined by X-ray analysis to be $2 \pm 20 \mathrm{~nm}$ in width and $2 \pm 17 \mathrm{~nm}$ in thickness (depending on the cellulose sample used).

\section{COMPUTER ANALYSIS OF CELLULOSE}

Computer modelling has been used to study cellulose for many decades and some of the results are discussed below. Many of the calculations carried out on cellulose have used varying levels of constraint to reduce the computing power and time required to obtain a result.
This method of analysis has been used in combination with more conventional methods of analysis to test the viability of proposed models. Due to the small amount of diffraction data available for cellulose in comparison to the number of atoms that must be located in each of three dimensions, it has been the practise to construct a stereochemically reasonable polymer model. The diffraction intensity information is then used to locate the chain within the unit cell and to determine the actual position of the hydroxymethyl groups (French and Murphy, 1977). Several chain arrangements were generated in an effort to reduce the reliability factor (R) for X-ray data. Attempts were made to produce a result which fitted in with expectations for cellulose, based on information possessed for related structures. X-ray diffraction of single crystals is the only method that can provide, definitively, bond length, bond angles and characteristic geometry for compounds (Henrissat et al., 1987).

However, in the study of polymers by diffraction methods a proposed model has to be created and hence the result is not absolute. Therefore, it is important to refer to single crystal studies that provide data on which to base cellulose models. By adding a mathematical approach to the quest for the 'best fit', proposed models were analysed by computer based stereochemical modelling (Tasker et al., 1994). Statistics were applied to determine the probabilities of the chain conformations and arrangements occurring. As with all methods used for the structural determination of cellulose, the results of computer analysis cannot be termed absolute, as they depend on the level of sophistication of the instrumentation and the quality of the algorithms used.

\section{ADVANCED MODELS OF CELLULOSE}

A structure for the single-chain Iá cellulose unit cell was built by French et al. (1993). The existence of two polymorphs of native cellulose i.e. $\mathrm{I}_{\alpha}$ and $\mathrm{I}_{\beta}$ was also investigated by Heiner et al. (1995). They reported the monoclinic $\left(\mathrm{I}_{\beta}\right)$ phase was $8.7 \mathrm{~kJ} \mathrm{~mol}^{-1}$ cellobiose ${ }^{-1}$ more stable than the triclinic phase. This agrees with the findings of Aabloo et al. (1994), which were obtained by using both the rigid-ring method PLMR and the fulloptimization molecular mechanics program MM3(90). Reisling and Brickmann (1995) devised a model for a 
cellulose chain consisting of $\beta$-glucose hexamers. Models have been built for sections of native crystalline cellulose, for example that of French et al. (1993) which contained 24 to 32 monosaccharide residues and that of O'Sullivan (1995) which was a 16 cellulose chain model of a cellulose microfibril. Non-bond inter and intramolecular interactions have been calculated for cellulose molecules and similar systems to determine what the stabilizing forces are in a cellulose microfibril. It has been stated by Kooijman et al. (1992) that crystal packing of a compound is determined solely by intermolecular interactions. While Pizzi and Eaton (1984, 1987) found that hydrogen bonding and van der Waals forces are the predominant factors in the stabilization of the minimum energy conformations of cellobiose and methyl-â-cellobioside and of the crystalline zone for cellulose II and cellulose I. They also found that cellulose II was more stable than cellulose I. Due to the importance of non-bond interactions in determining minimum energy conformations it is vital that they are included in the force field that is used for modelling cellulose. However, as the magnitude of such forces decrease greatly with increases in interatomic distances, the interaction energy between two atoms may be calculated when the interacting atoms lie within a specified cut-off range, thereby reducing computation time significantly. Heiner et al. (1995) produced models of $\mathrm{I}_{\alpha}$ and $\mathrm{I}_{\beta}$ cellulose using the Gromos 87 force field on which hydroxymethyl conformations were carried out. Molecular modelling may be used to study physical properties of cellulose as shown in the work of Leeflang et al. (1992), who studied the elastic modulus of cellulose I and II by molecular mechanics. Computer simulation is now used in conjunction with many other methods of analysis such as diffraction studies as discussed above, NMR spectroscopy (Henrissat et al., 1987 and Heiner et al., 1995) and surface analysis (O'Sullivan, 1995 and Woodcock et al., 1995).

\section{Conclusion}

From the above discussion it is obvious that the structure of cellulose is complex and its study requires the consideration of many factors. Investigation into the many aspects of cellulose structure is being continued by research groups worldwide and new results appear in the literature constantly. This trend shall continue as more is learned about cellulose by the application of an increasing number of techniques. All knowledge gained about cellulose structure is vital to life today as cellulose and its derivatives are used in so many industrial applications.

\section{ACKNOWLEDGEMENTS}

The authors are thankful to Madhya Pradesh M.P.
Pollution Control Board Bhopal and Head, Department of Biological Sciences, R.D. University, Jabalpur, for laboratory facilities. Also thanks to Municipal Corporation of Jabalpur for his support. Ministry of Environment and Forest New Delhi is also thankfully acknowledged for financial support.

\section{REFERENCES}

Atalla, R.H., Hackney, J.M., Uhlin, I. and Thompson, N.S. (1993). Hemicelluloses as structure regulators in the aggregation of native cellulose. Int. J. Biol. Macromol., 15:109-112.

Atalla, R.H. and Vanderhart, D.L. (1989). Studies on the structure of cellulose using Raman spectroscopy and solid 13C NMR. In cellulose and Wood: Chemistry and Technology, proceedings of the tenth cellulose conference (C. Schuerch, ed.). New York: John Wiley and Sons. 169187.

Andress, K.R. (1929). The X-ray diagram of mercerized cellulose. Zietschrift Physikalische Chemie Abstracts B. 4:190-206.

Ahmed, A. U., Ahmed, N., Aslam, J., Butt, N.M., Khan, Q.H. and Atta, M.A. (1976). Neutron diffraction on studies of the unit cell of cellulose II. J. Pol. Sci. Polymer Letters Edition., 14:561-564.

Aabloo, A., French, A.D., Mikelsaar, R.H. and Pertsin, A.J. (1994). Studies of crystalline native celluloses using potentialenergy calculations. Cellulose., 1:161-168.

Brown, R., M. ,Jr. and Saxena, I. M. (2000). Cellulose biosynthesis: a model for understanding the assembly of biopolymers. Plant P hysiol. Biochem., 38:57-67.

Blackwell, L. (1982). The macromolecular organization of cellulose and chitin. In Cellulose and other natural polymer systems (R. M. Brown, Jr., ed..). New York: Plenum Press.

Blackwell, L. and Machessult, R.H. (1971). Infrared spectroscopy of cellulose. In cellulose and cellulose derivatives (N. Bikales and L.E. Segal, eds) New York: Willey-Interscience.

Belton, P. S., Tanner, S.F., Cartier, N. and Chanzy, H. (1989). High resolution solid state ${ }^{13} \mathrm{C}$ NMR spectroscopy of tunicin, an animal cellulose. Macromolecules., 22: 16151617.

Buleon, A. and Chanzy, H. (1978). Single crystals of cellulose II. J . Polymer Sci., 16:833-839.

Buleon, A. and Chanzy, H. (1980). Single crystals of cellulose IV: preparation and properties. Ibid. 18:1209-1217.

Chanzy, H., Henrissat, B. and Vuong, R. (1986). Structural changes of cellulose crystals during the reversible transformation cellulose I'TMIII in Valonia. Holzforschung., 40:25-30.

Chanzy, H., Henrissat, B., Vincendon, M., Tanner, S.F. and Belton, P.S. (1987). Solid state C-13-NMR and electronic microscopy study on the reversible cellulose I'TMcellulose III transformation in Valonia. Carbohydrate Res., 160:1-11.

Chanzy, H. (1990). Aspects of cellulose structure. In cellulose source and exploitation: industrial utilization biotechnology and physico-chemical properties (J.F. Kennely, G.O. Phillips and P. A. Williams, eds). Chichester, U.K: Ellis Horwood, pp. 3-12. 
Debzi, E. M., Chanzy, H., Sugiyama, J., Tekely, P. and Excoffier, G. (1991). The Iá' !Ia transformation of highly crystalline cellulose by annealing in various mediums. Macromolecules., 24:6816-6822.

Dudley, R.L., Fyfe, C.A., Stephenson, P.J., Deslandes, Y., Hamer, G. K. and Marchessault, R. H. (1983). Highresolution ${ }^{13} \mathrm{C} \mathrm{CP} / \mathrm{MAS} / \mathrm{NMR}$ spectra of solid cellulose oligomers and the structure of cellulose II. J. Am. Chem. Soc., 105:2469-2472.

Dennis, D. T. and Preston, R.D. (1961). Constitution of cellulose microfibrils. Nature., 191:667-668.

Erata, T., Shikano, Takai, M. and Hayashi, J. (1995). NMRstudies on the structure of cellulose two dimensional solidstate NMR approach. Macromolecular Symposia. 99:2529.

Fink, H.P., Philipp, B., Paul, D., Serimaa, R. and Paakkari, T. (1987). The structure of amorphous cellulose as revealed by wide angle X-ray scattering. Polymer 28:1265-1270.

Fengel, D. (1992). Characteristics of cellulose by deconvoluting the $\mathrm{OH}$ valency range in FTIR spectra. Holzforschung., 46:283-288.

Fengel, D. and Stoll, M. (1989). Crystals of cellulose grown from TFA solution. Wood Sci. Tecnol., 23:85-94.

Fengel, D. and Wegner, G. (1989). In Wood: Chemistry, Ultrastructure, Reactions. Berlin, New York: de Gruyter, p. 66.

French, A.D., Miller, D.P. and Aabloo, A. (1993). Miniature crystal models of cellulose polymorphs and other carbohydrates. Int. J. Biol. M acromolecules., 15:30-36.

French, A.D. and Murphy, V.C. (1977). A virtual bond modeling study of cellulose I. In Cellulose chemistry and technology ACS symposium Series. 48 (J. C. Arthur, Jr. ed.). Washington DC: American Chemical Society, pp. 12-29.

Gardiner, E.S. and Sarko, A. (1985). Packing analysis of carbohydrates and polysaccharides. 16. The crystal structures of cellulose $\mathrm{IV}_{\mathrm{I}}$ and $\mathrm{IV}_{\mathrm{II}}$. C an. J . Chemistry., 63:173180.

Gardner, K.H. and Blackwell, J. (1974). The structure of native cellulose. Biopolymers., 13:1975-2001

Gardner, K.H. and Blackwell, J. (1974a). The structure of native cellulose. Biopolymers., 13:1975-2001.

Honjo, G. and Watanabe, M. (1958). Examination of cellulose fibre by the low temperature specimen method of electron diffraction and electron microscopy. Nature., 181:326-328

Hayashi, J. Yamada, T. and Shimizu, Y.L, (1989). Memory phenomenon of the original cristal structure inn allomorphs of Na-cellulose. In cellulose and Weed: Chemistry and Technology, Proceedings ogg the tenth cellulose conference (C. Sthuerch, ed.). New York: John Wiley and Sons, pp. 77107.

Hermans, P.H. (1949). Physics and chemistry of cellulose fibres. New York: Elsevier., pp. 13-20.

Hermans, P.H. and Weidinger, A. (1949). X-ray studies on the crystallinity of cellulose. J. Polymer Sci., 4:135-144.

Heyn, A. N.J. (1966). The microcrystalline structure of cellulose in cell walls of cotton, ramie and jute fibres as revealed by negative staining of sections. J . Cell Biol., 29:181197.

Hanley, S.J., Giasson, J., Revol, J.F. and Gray, D.G. (1992). Atomic force microscopy of cellulose microfibrils comparison with transmission electron-microscopy.
Polymer., 33:4639-4642.

Henrissat, B., Perez, S., Tvaroska, I. and Winter, W. (1987). Multidisciplinary approaches to the structure of model compounds for cellulose II. In The Structure of Cellulose. Washington DC: American Chemical Society, pp. 38-66.

Heiner, A.P., Sugiyama, J. and Teleman, O. (1995). Crystalline cellulose $\mathrm{I}_{\alpha}$ and $\mathrm{I}_{\beta}$ studied by molecular dynamics simulation. Carbohydrate Res.,273:207-223.

Horii, F., Hirai, A. and Kitamaru, R. (1982). Solid-state highresolution ${ }^{13} \mathrm{C}$ NMR studies of regenerated cellulose sample with different crystallinities. Polymer Bulletin. 8:163.11

Horii, F., Hirai, A. and Kitamaru, R. (1987b). CP/MAS C-13 NMR spectra of the crystalline components of native cellulose. Macromolocules. 20:2117-2120.

Hon, D.N.-S. (1996). Cellulose and its derivatives: Structure, Reactions and Medical uses. In: Polysaccharides in medicinal Applications. Dumitriu D (ed.) Marcel Dekker, New York, pp. 87-105.

Kolpak, F.J. and Blackwell, J. (1976). Determination of the structure of cellulose II. M acromolecules., 9:273-278.

Kulshreshta, A. K. and Dweltz, N. E. (1973). Paracrystalline lattice disorder in cellulose I. Reappraisal of application of 2-phase hypothesis to analysis of powder X-ray diffractograms of native and hydrolysed cellulosic materials. J. Polymer Sci.: Polymer Physics Edition. 11:487-497.

Kuutti, L., Peltonen, J., Pene, J. and Teleman, O. (1995). Identification and surface-structure of crystalline cellulose studied by atomic force microscope. J ournal of M icroscopyOxford., 178:1-6.

Kuga, S., Takagi, S. and Brown, R.M.Jr. (1993). Native folded chain cellulose II, Polymer. 34:3293-3297.

Kooijman, J., van Eijck, B.P. and Kroon, J. (1992). Molecular dynamics simulations of crystal structures containing charged molecular structure of fibers. Papier- Fabr., 36:345348 .

Leeflang, B.R., Vliegerthart, J.F.G., Kroon-Batenburg, L.M.J., van Eijck, B.P. and Kroon, J. (1992). A ${ }^{1} \mathrm{H}-\mathrm{NMR}$ and MD study of intramolecular hydrogen bonds in methyl- $\alpha$ cellobioside. Carbohydrate Research., 230:41-61.

Lin, K.W., Ladisch, M.R., Schaefer, D.M., Noller, C.H., Lechtenberg, V. and Tsao, G.T. (1981). Review on effect of pretreatment on digestibility of cellulosic materials. AiChE Symposium Series, 77(207): 102-106.

Lynd, L.R., Wyman, C.E. and Gerngross, T.U. (1999). Biocommodity engineering. Biotechnol. Prog., 15: 777-793.

Linder, M., Mattinen, M.L., Konttelli, M., Lindeberg, G. Stahlberg, J., Drakenberg, T., Reinikainen, T., Pettersson, G. and Annila, A. (1995). Identification of functionally important amino acids in the cellulose-binding domain of Trichoderma ressei cellobiohydrolase I. Protein Science, 4: 1056-1064.

Lee, Y.H. and Fan, L.T. (1982). Kinetic studies of enzymatic hydrolysis of insoluble cellulose I. Biotechnology and Bioengineering., 24:2383-2406.

Liang, C.Y. and Marchessault, R.H. (1959). Infrared spectra of crystalline polysaccharides. I. Hydrogen bonds in native cellulose. J. Polymer Sci., 37:385-395.

Marchessault, R.H. and Sundararajan, P.R. (1983). In Cellulose, in the polysaccharides. New York: Academic Press, p.11.

Marchessault, R.H. and Sundararajan, P.R. (1983). Cellulose, 
In G. O. Aspinall (ed.), The polysaccharides. Academic press, inc., New York, N.Y. Vol. 2. pp. 11-95

Marchessault, R. H. and Sarko, A. (1967). X-ray structure of polysaccharides. In Advanced carbohydrate Chemistry 22: (M.L. Wolfrom, ed.). New york: Academic Press, pp. 421483.

Mann, J. and Marrinan, H.J. (1958). Crystalline modification of cellulose. Part II. A study with plane polarized infrared radiation. J. Polymer Sci., 32:357-370.

Meyer, K.H. and Misch, L. (1937). Positions des atomes dans le nouveau modele spatial de la cellulose. H elvetica $\mathrm{C}$ himica Acta., 20:232-245.

Meyer, K.H. and Mark, H. (1928). The structure of the crystallized components of cellulose. B erichte der D eutschen Chemica Gesellschaft., 61(B): 593-614.

Morosoff, N. (1974). Never dried cotton fibres. Crystallinity and crystallite size. J ournal of Applied Polymer Science, 18:1837-1854.

Nishimura, H., Okano, T., Sarko, A. (1991a). Mercerization of cellulose. 5. Crystal and molecular structure of Na-cellulose I. M acromolecules., 24:759-770.

Nishimura, H., Okano, T., Sarko, A. (1991b). Mercerization of cellulose. 5. Crystal and molecular structure of Nacellulose IV. Ibid., 771-778.

Nyburg, S. C. (1961). Fibrous macromolecular substances. In X-ray analysis of organic structures (L. F. Fieser and M. Fieser, eds). New York: Academic Press, pp. 302-314.

Okamura, K. (1991). Structure of cellulose. In wood and Cellulosic Chemistry (D. N.S. Hon and N. Shiraishi, eds). New York: Marcel Dekker, pp. 89-111.

Okano, T. and Sarko, A. (1985). Mercerization of cellulose. II. Alkali-cellulose intermediates and a possible mercerization mechanism. Ibid., 30:325-332.

Okano, T., Koyanagi, A., Kondo, Y. and Seko, A. (1989). Structural variation of native cellulose related to its source. In cellulose and wood: chemistry and technology, proceeding of the tenth cellulose conference (C. Schuerch ed.) New York: John Willy and Sons, pp. 53-65.

Okano and Sarko, A. (1984). Mercerization of Cellulose I. Xray diffraction evidence for intermediate structures. J . A ppl. Polymer Sci., 29: 4175-4182.

Ott, E., Spurlin, H., Graffine, M. and Mark, H. (1954). Cellulose and cellulose derivatives. Interscience, New York, pp 217-300.

O'Sullivan, A. C. (1995). Modelling of cellulose molecule interactions. Ph.D thesis. University of Wales, Bangor, Gwynedd, UK

Paakkari, T., Serimaa, R. and Fink, H.P. (1989). The structure of amorphous cellulose. Acta Polymerica., 40:731-734.

Pandey, A., Mathew, G.M., Sukumaran, R.K., Singhania, R.R. (2008). Progress in research on fungal cellulases for lignocellulose degradation. J. Scientific \& Industrial Research., 67: 898-907.

Pizzi, A. and Eaton, N. (1984). The structure of cellulose by conformational analysis 1 . Cellobiose and Methyl- $\alpha-$ cellobioside. J ournal of M acromolecular Science C hemistry, A21:1443-1446.

Pizzi, A. and Eaton, N. (1987). The structure of cellulose by conformational analysis. Part 4. Crystalline cellulose II, I bid., 24:901-918.

Preston, R.D. (1975). X-ray analysis and the structure of the components of plant cell walls. Physics Reports, 21: 183226.

Preston, R.D. (1986). Natural celluloses. In cellulose: structure, modification and hydrolysis (R.A. Young and R.M. Rowell, eds). New York: John wiley and sons, pp. 3-27.

Reis, D., Vian, B., Chanzy, H. and Roland, J.C. (1991). Liquid crystal type assembly of native cellulose-glucuronoxylans extracted from plant cell wall. Biology of the cell., 73:173-178.

Revol, J. F. and Goring, D.A. (1983). Directionally of the fibre c-axis of cellulose crystallites in microfibrils of Valonia ventricosa. Polymer, 24:1547-1550.

Reinikainen, T., Teleman, O., Teeri, T.A. (1995). Effect of $\mathrm{pH}$ and high ionic strength on the adsorption and activity of native and mutated cellobiohydrolase I from Trichoder ma ressei. Proteins, 22:392-403.

Reisling, S. and Brickmann, J. (1995). Theoretical invertigation on the structure and physical properties of cellulose. Macromolecular theory and simulations. 4:725-743.

Roche, E. and Chanzy, H. (1981). Electron microscopy study of the transformation of cellulose I into cellulose III $_{I}$ in Valonia. Int J. Biol. M acromolecules., 3 : 201-206.

Sarko, A. and Muggli, R. (1974). Packing analysis of carbohydrates and polysaccharides. III. Valonia cellulose and cellulose II. M acromolecule., 7:486-494.

Sarko, A. (1987). Cellulose- How much do we know about its structure. In wood and cellulosics: Industrial utilization, biotechnology, structure and properties (J.F. Kennedy, ed.). Chichester, U.K.: Ellis Horwood, pp 55-70.

Sarko, A. (1978). What is the crystalline structure of cellulose. Tappi, . 61: 59-61.

Simon, I., Scheraga, H. A. and Manley, R. St. J. (1988a). Structure of cellulose. 1. Low-energy conformations of single chains. M acromolecule, 21:983-990.

Shefter, E. and Trublood, K.N. (1965). The crystal and molecular structure of $\mathrm{D}(+)$ barium uridine $-5^{1}$ phosphate. Acta Crystallographica, 18: 1067-1077.

Sponsler, O. and Dore, W.H. (1926). The structure of ramie cellulose as derives from X-ray data. Fourth Colloid Symposium M onograph., 41:174-202.

Stipanovic, A.J. and Sarko, A. (1976). Packing analysis of carbohydrates and polysaccharides. 6 . Molecular and crystal structure of regenerated cellulose II. M acromolecules, 9:851857.

Sugiyama, J., Persson, J. and Chanzy, H. (1991). Combined IR and electronic diffraction study of the polymorphism of native cellulose. M acromolecules., 24:2461-2466.

Sugiyama, J. and Okano, T. (1989). Electron microscopic and X-ray diffraction study of cellulose III $_{\mathrm{I}}$ cellulose conference (C. Schuerch, ed.). New York: John Wiley and Sons, pp. 119-127.

Sugiyama, J.(1992). Crystal forms of native cellulose. M okuzai Gakkaishi., 38:723-731.

Tasker, S., Badyal, J.P.S., Backson S.C.E. and Richards, R.W. (1994). Hydroxyl accessibility in celluloses. Polymer, 35:4717-4721.

Tormo, J., Lamed, R., Chirino, A.J., Morag, E., Bayer, E.A., Shoham, Y. and Steitz, T.A. (1996). Crystal structure of a bacterial family III cellulose-binding domain: a general mechanism for attachment to cellulose. EMBO J ournal., 15:5739-5751. 
Tsuboi, M. (1957). Infrared spectrum and crystal structure of cellulose. J. Polymer Sci., $25: 159-171$.

Tuomela, M., Vikman, M., Hatakka, A. and Itavaara, M. (2000). Biodegradation of lignin in a compost environment: a review. Bioresource Tachnol., 72 : 169-183.

Verlhac, C., Dedier, J. and Chanzy, H. (1990). Availability of surface hydroxyl groups in Valonia and bacterial cellulose. J. Polymer Sci.: Part A: Polymer Chemistry. 28:1171-1177. van Soest, P.J. (1994). Nutrition ecology of the ruminant, $2^{\text {nd }}$ ed. Cornell University Press, Tthaca, N.Y.

Vyas, N.K. (1991). Atomic feature of protein carbohydrate intetraction. Current 0 pinion in Structural Biology., 1 : 732 740.

Woodcock, C. and Sarko, A. (1980). Packing analysis of carbohydrates and polysaccharides. II Molecular and crystal structure of native ramie cellulose. Macromolecules, 13:1183-1187.

Wellard, H.J. (1954). Variation in the lattice spacing of cellulose.
J. Polymer Sci., 13:471-476.

Woodcock, S., Henrissat, B. and Sugiyama, J. (1995). Docking of Congo red to the surface of crystalline cellulose using molecular mechanics. Biopolymers, 36:201-210.

Walton, A.G. and Blackwell, J. (1973). In biopolymers. Vol 22, New York: Academic Press, p.468.

Yamamoto, H. and Horii, F. (1994). In situ crystallization of Bacterial cellulose I. Influences of polymeric additivesw, stirring and temperature on the formation cellulose $\mathrm{I}_{\mathrm{a}}$ and $\mathrm{I}_{\mathrm{a}}$ as revealed by cross polarization/magic angle spinning $(\mathrm{CP} /$ MAS) ${ }^{13} \mathrm{C}$ NMR spectroscopy. Cellulose, $1: 57-66$.

Yamamoto, H. and Horii, F. (1993). CP/MAS 13C NMR analysis of the crystal transformation induced for Valonia Cellulose by annealing at high temperature. M acromolecules, $26: 1313-1317$.

Zeronium, S.H. and Ryu, H.S. (1987). Properties of cotton fibres containing the cellulose IV crystal structure. J. A ppl. Polymer Sci., $33: 2587-2604$. 